\title{
Allocation of dry matter in Eucalyptus grandis seedlings in response to nitrogen supply
}

\author{
R.N. Cromer ${ }^{1}$ and P.G. Jarvis ${ }^{2}$ \\ ${ }^{1}$ CSIRO Division of Forestry and Forest Products, Box 4008, Queen Victoria Terrace, A.C.T. 2600, \\ Australia, and \\ ${ }^{2}$ Department of Forestry and Natural Resources, University of Edinburgh, The Kings Buildings, \\ Mayfield Road. Edinburgh EH9 3JU, U.K.
}

\section{Introduction}

It is well established that a high level of nutrient supply increases shoot growth. relative to root growth in trees and a shift in carbon allocetiun to roots was observed in seedlings of Eucalyptus delegatensis with increasing nutrient stress (Cromer et al., 1984). This shift can have a major effect on stemwood production but similar studies have not been reported for $E$. grandis.

Despite reports of (often dramatic) increases in growth of $E$. grandis following application of nutrients, we have little understanding of physiological mechanisms responsible for such responses. It is recognised that leaf area is a major determinant of plant productivity but the importance of leaf development in comparison with dry matter partitioning and rate of $\mathrm{CO}_{2}$ assimilation is not well understood (see Cannel, 1985). In this paper, we examine the way in which rate of nitrogen supply to $E$. grandis seedlings affects allocation of dry matter.

\section{Material and Methods}

Seedlings of Eucalyptus grandis were grown in a naturally lit glass house with day/night temperatures of $27 / 21^{\circ} \mathrm{C}$, for 8 and $16 \mathrm{~h}$, respectively. Seedlings were grown in 5 aeroponic 'growth units' designed to permit seedlings to grow at constant relative growth rates $\left(R_{\mathrm{g}}\right)$ and stable internal nutrient concentrations (Ingestad and Lund, 1986). Nutrient solutions, made up so that nitrogen was the element most limiting growth, were added to circulating solutions at relative addition rates between 0.04 and 0.12 $\mathrm{d}^{-1}$. This technique enabled stable seedling nitrogen concentrations [N] and $R_{g}$ to be maintained during experimental periods of $40-60 \mathrm{~d}$ in 4 growth units. Seedlings from each growth unit were harvested on 4 occasions at intervals of 7-14 d depending upon growth rate.

\section{Results}

$R_{\mathrm{g}}$ and [N] were relatively stable over time for each treatment (data not shown). Allocation of dry matter to stems and roots was examined in relation to leaf mass and data from each harvest and treatment 


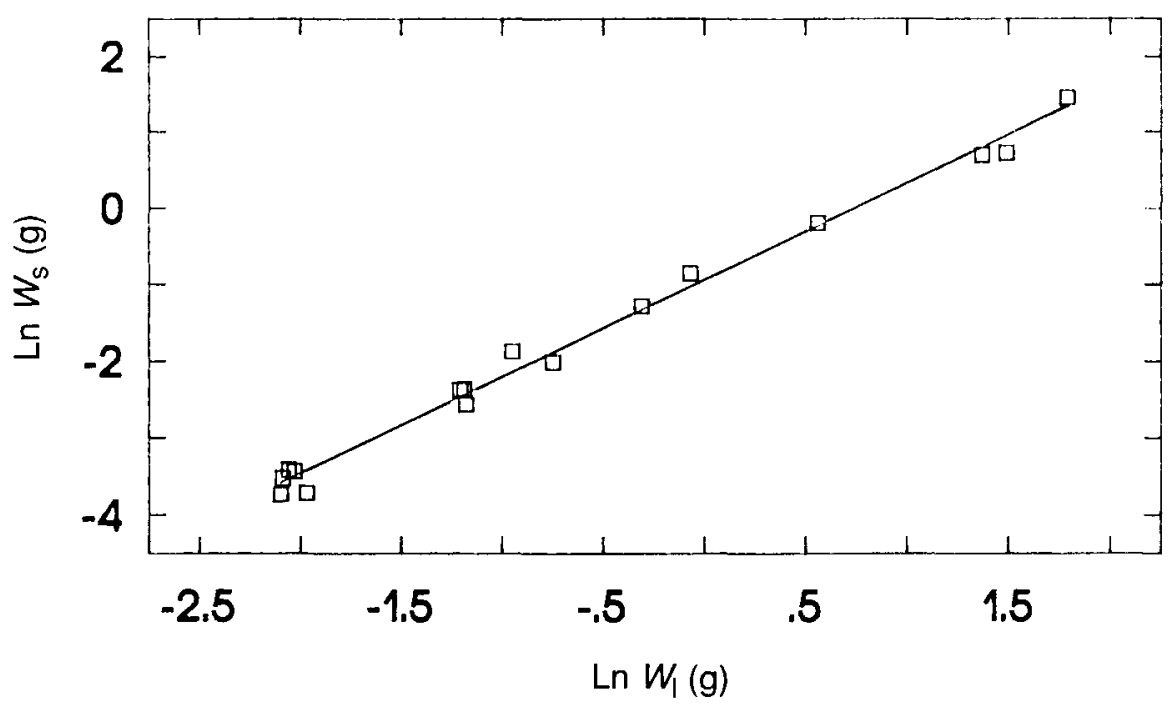

Fig. 1. Allometric relationships between stem mass $\left(W_{\mathrm{s}}\right)$ and leaf mass $\left(W_{1}\right)$ of $E$. grandis seedlings grown at 4 relative nitrogen addition rates. $\operatorname{Ln} W_{\mathrm{S}}=-0.934+1.261 \cdot \operatorname{Ln} W_{1}\left(r^{2}=0.992\right)$.

combination were pooled and tested using an allometric relationship (Ledig, 1983):

$$
\operatorname{Ln} W_{\mathrm{s}}=\alpha+\beta \cdot \operatorname{Ln} W_{1}
$$

where $W_{\mathrm{s}}$ is stem mass, $W_{1}$ is leaf mass, $\alpha$ is a constant and $\beta$ is the slope. A strong linear correlation $\left(r^{2}=0.992\right)$ was found between $\operatorname{Ln} W_{\mathrm{s}}$ and $\operatorname{Ln} W_{1}$ as shown in Fig. 1. Leaf growth was initially a stronger sink for carbon than stem growth and allocation of dry matter was less to stems than leaves. However, the slope of the regression exceeded unity and this difference between stem and leaf mass diminished with ontogeny.

A satisfactory relationship between root mass $\left(W_{r}\right)$ and $W_{1}$ was not obtained using eqn 1 and an additional term was inserted to account for the effect of nutrient treatments:

$\operatorname{Ln} W_{\mathrm{r}}=\alpha+\gamma[\mathrm{N}]+\beta \cdot \operatorname{Ln} W_{1}$
This resulted in a strong linear correlation $\left(r^{2}=0.988\right)$ between $\operatorname{Ln} W_{r}$ and $\operatorname{Ln}$ $W_{r}$ but with a major influence of $[N]$ on allocation as shown in Fig. 2. The regression slope was not significantly different from unity and the ratio of $W_{r}$ to $W_{1}$ was 1.0 when $\left[\mathrm{N}\right.$ ] approximated $16 \mathrm{mg} \cdot \mathrm{g}^{-1}$. At values of [N] above this, root to leaf ratio was less than 1.0.

\section{Discussion}

Many investigators have sought to describe effects of environmental variables or silvicultural treatments on growth and allocation of dry matter by analysis of shoot/root ratio (mass of top/mass of root) but use of this ratio has frequently led to incorrect interpretations because of failure to recognise that it changed with ontogeny 


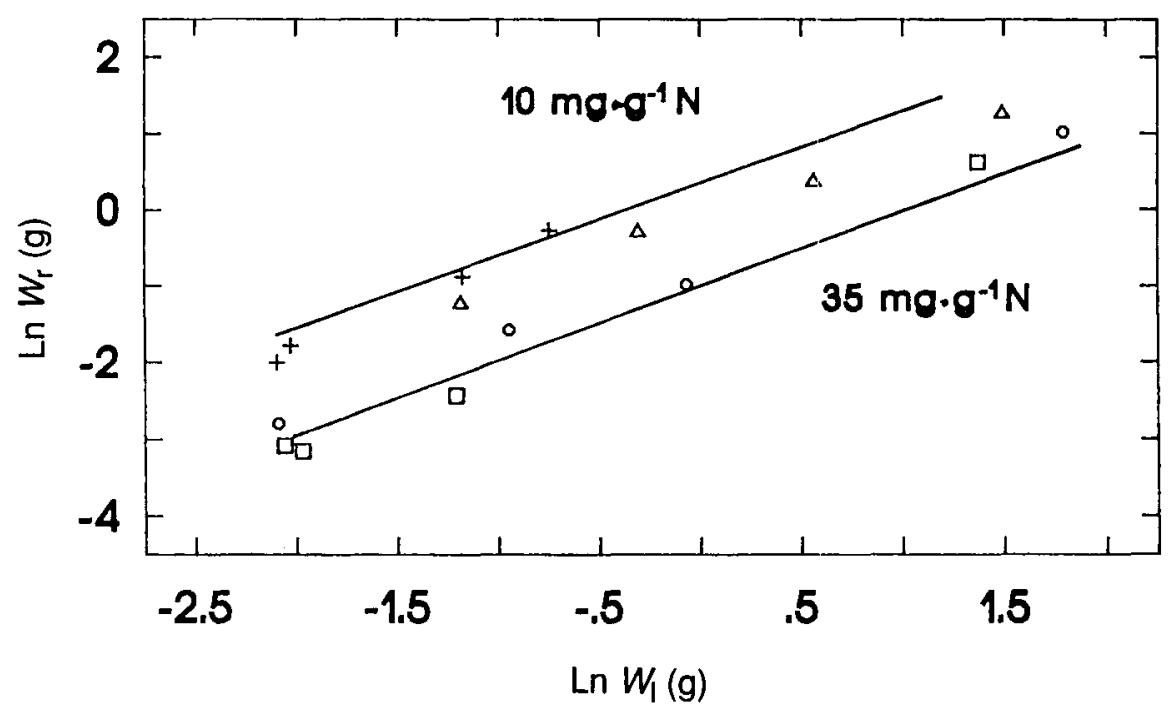

Fig. 2. Allometric relationships between root mass $\left(W_{r}\right)$ and leaf mass $\left(W_{1}\right)$ of $E$. grandis seedlings grown at 4 relative nitrogen addition rates. $\operatorname{Ln} W_{r}=0.881-0.054[N]+0.982 \cdot \operatorname{Ln} W_{1}\left(r^{2}=0.988\right)$.

(Ledig et al., 1970). Comparison of shoot/root ratio of plants of different sizes is therefore open to serious criticism.

Comparison of regression coefficients of the allometric formula has been suggested as the most useful test of allocation between root and shoot, where different treatment effects will appear as different regression slopes, $\beta$ in eqn 1 (Ledig et al., 1970). However, examination of allometric relationships between foliage and root mass in $E$. grandis demonstrated that nitrogen nutrition influenced partitioning such that an additional term was required to form eqn 2. This term incorporating [N] had the effect of altering regression intercept, but had no influence on slope $\beta$ (Fig. 2.). Under conditions of stable relative nutrient addition rate and thus stable $R_{\mathrm{g}}$, a constant slope between foliage and root mass is to be expected or differences in mass of these organs would increase with ontogeny. [N] had a strong influence on the ratio of $W_{r}$ to $W_{1}$ which was stable across a wide range of plant sizes.

Slopes of allometric relationships between $W_{s}$ and $W_{1}$ would be expected to exceed one in forest trees and absolute values of these slopes may provide an indicator of comparative efficiency for wood production. In the present experiment, this slope was 1.26 for E. grandis, but of greater interest is the fact that nutrient treatment had no effect on slope or intercept of this allometric relationship. Some reports dealing with relationships between shoot and root indicate that allocation to stem is influenced by nutrition (e.g., Ingestad and Lund, 1979). However, our data suggest that above versus below ground allocation depends upon [N] but a conservative relationship exists between aboveground components (stem and foliage). 


\section{Conclusions}

An allometric relationship derived between $W_{1}$ and $W_{\mathrm{s}}$ in $E$. grandis was dependent upon organ mass, with greater allocation to stem occurring with ontogeny (slope = 1.26). This relationship was not influenced by seedling $[\mathrm{N}]$. On the other hand, allometric relations between $W_{1}$ and $W_{r}$ were dependent upon seedling $[N]$, which influenced regression intercept but not slope, which was equal to unity. Environmental influences on allocation of dry matter, among leaf, stem and root components in woody perennials, are complex and nutrient effects are so profound that omission of this variable will seriously compromise results.

\section{Acknowledgments}

The authors wish to thank David Bellingham, Wanda Pienkowska and Leroy Stewart for excellent assistance with various aspects of this experiment. We are indebted to Paul Kriedemann and Ross McMurtrie for discussion of concepts presented and constructive criticism of the manuscript.

\section{References}

Cannell M.G.R. (1985) Dry matter partitioning in tree crops. In: Attributes of Trees as Crop Plants. (Cannel M.G.R. \& Jackson J.E., eds.), Inst. Terrestrial Ecol. Huntingdon, U.K. pp. 160193

Cromer R.N., Wheeler A.M. \& Barr N.J. (1984) Mineral nutrition and growth of eucalyptus seedlings. New Zealand J. For. Sci 14, 229-239 Ingestad T. \& Lund A.B. (1979) Nitrogen stress in birch seedlings. I. Growth technique and growth. Physiol. Plant. 45, 137-148

Ingestad T. \& Lund A.B. (1986) Theory and techniques for steady state mineral nutrition and growth of plants. Scand. J. For. Res. 1, 439-453

Ledig F.T. (1983) The influence of genotype and environment on dry matter distribution in plants. In: Plant Research and Agroforestry. (Huxley P.A., ed.), Intl. Council for Res. in Agroforestry, Nairobi, pp. 427-454

Ledig F.T., Bormann F.H. \& Wenger K.F. (1970) The distribution of dry matter growth between shoot and roots in loblolly pine. Bot. Gaz. 131, 349-359 